\title{
Electrochemical Methodology for NSAID's Determination and its Interaction with Steroid Dexamethasone
}

\author{
Sobia Tahir ${ }^{l}$, Kousar Yasmeen ${ }^{1, *}$, Muddasir Hanif, , , Obaid Khaliq ${ }^{1}$, Haji Muhammad ${ }^{1}$, \\ Hafsa ${ }^{1}$, Iftikhar Ahmed Tahiri ${ }^{1}$, Sajid Jahangir ${ }^{1}$, Syed Tahir Ali ${ }^{1}$ \\ ${ }^{1}$ Department of Chemistry, Faculty of Science, Federal Urdu University of Arts, Science and \\ Technology, Gulshan-e-Iqbal Campus, Karachi-75300, Pakistan \\ ${ }^{2}$ Department of Chemistry and Chemical Engineering, Jiangxi Normal University, Nanchang, Jiangxi, \\ 330022, People's Republic of China \\ *E-mail: muddasirhanif@yahoo.com (M. Hanif), kauseryasmeen@ fuuast.edu.pk (K. Yasmeen)
}

doi: $10.20964 / 2019.06 .16$

Received: 31 January 2019/ Accepted: 18 March 2019 / Published: 10 May 2019

The new generations of Non-Steroidal Anti-inflammatory Drugs (NSAIDS) are COX-2 selective cyclooxygenase- 2 inhibitors (analgesic and anti-inflammatory) capable to cause adverse gastrointestinal events due to drug interactions between one or more co-administered medicines. This causes alteration of the efficacy or toxicity of the co-administered drug. This study presents an electrochemical method (CV) evaluation to study the interactions of Naproxen Sodium and Piroxicam with Dexamethasone (Steroid) under optimized conditions. The proposed method is electrochemically diffusion controlled as both drugs showed different diffusion coefficients (Piroxicam: $2.188 \times 10^{-7}$; Naproxen Sodium: $\left.3.755 \times 10^{-5}\right)$. The method has good reproducibility and validated according to ICH guide lines $\left(R^{2}=\right.$ 0.9994 for Naproxen Sodium and 0.9991 for Piroxicam). The interactions were confirmed by the FTIR studies indicated the variation of wave number and intensity of significant peaks thereby revealed possible interaction sites.

Keywords: Cyclic voltammetry, FTIR, NSAIDs, Piroxicam, Naproxen Sodium, Dexamethasone.

\section{$\underline{\text { FULL TEXT }}$}

(C) 2019 The Authors. Published by ESG (www.electrochemsci.org). This article is an open access article distributed under the terms and conditions of the Creative Commons Attribution license (http://creativecommons.org/licenses/by/4.0/). 